Research Paper

\title{
HES1 promotes extracellular matrix protein expression and inhibits proliferation and migration in human trabecular meshwork cells under oxidative stress
}

\author{
Linqi Xu ${ }^{1,2, *}$, Yan Zhang ${ }^{1, *}$, Ruru Guo ${ }^{1, *}$, Wencui Shen ${ }^{1,2}$, Yan $\mathbf{Q i}^{1,2}$, Qingsong Wang ${ }^{2}$, \\ Zhenglong Guo ${ }^{2}$, Chen $\mathbf{Q i}^{1}$, Haifang Yin ${ }^{2}$, Jiantao Wang ${ }^{1}$ \\ ${ }^{1}$ Tianjin Medical University Eye Hospital, Tianjin Medical University Eye Institute, College of Optometry and Ophthalmology, \\ Tianjin Medical University, Tianjin 300384, China \\ ${ }^{2}$ Tianjin Research Center of Basic Medical Sciences and Department of Cell Biology, Tianjin Medical University, Tianjin \\ 300070, China \\ *These authors have contributed equally to this work \\ Correspondence to: Jiantao Wang, email: wangjiantao65@126.com \\ Haifang Yin, email: haifangyin@tmu.edu.cn \\ Keywords: oxidative stress, glaucoma, trabecular meshwork, extracellular matrix, HES 1 \\ Received: November 22, $2016 \quad$ Accepted: February 07, $2017 \quad$ Published: February 23, 2017
}

\section{ABSTRACT}

Glaucoma is the leading cause of irreversible blindness. The most prevalent form of glaucoma is primary open-angle glaucoma (POAG). Oxidative stress is one of the major pathogenic factors of the POAG, and can elicit molecular and functional changes in trabecular meshwork cells, causing increased aqueous humor outflow resistance and elevated intraocular pressure. However, the regulatory mechanisms underlying oxidative stress-induced cell phenotypic changes remain elusive. Herein, we exposed primary human trabecular meshwork cells to the oxidative stress induced by $300 \mu \mathrm{M} \mathrm{H}_{2} \mathrm{O}_{2}$ for $2 \mathrm{~h}$, and found significantly up-regulated expression of extracellular matrix proteins and a transcription factor, hairy and enhancer of split-1 (HES1). The cell functions, including migration and proliferation, were impaired by the oxidative stress. Furthermore, HES1 shRNA abrogated the extracellular matrix protein up-regulation and rescued the functional defects caused by the oxidative stress; conversely, HES1 overexpression resulted in the molecular and functional changes similar to those induced by $\mathrm{H}_{2} \mathrm{O}_{2}$. These results suggest that HES1 promotes extracellular matrix protein expression and inhibits proliferative and migratory functions in the trabecular meshwork cells under oxidative stress, thereby providing a novel pathogenic mechanism underlying and a potential therapeutic target to the POAG.

\section{INTRODUCTION}

Glaucoma is the leading cause of irreversible blindness, and afflicts more than 70 million people worldwide [1]. More than $90 \%$ of glaucoma patients suffer from primary open-angle glaucoma (POAG) [2]. In the POAG, elevated intraocular pressure (IOP) is regarded as a critical risk factor for disease progression $[3,4]$. Although symptoms of the POAG can be relieved by lowering IOP [5, 6], the molecular mechanisms underlying IOP elevation remain elusive. Further insights into IOP regulatory mechanisms under pathological condition would facilitate development of a therapeutic modality to this vision-threatening disease.

Under normal condition, trabecular meshwork (TM) serves as the main regulator of IOP by controlling aqueous humor $(\mathrm{AH})$ outflow $[7,8]$. The extracellular matrix (ECM) proteins of TM cells undergo continuous turnover, and the equilibrium between production and degradation of the ECM proteins maintains a smooth drainage of $\mathrm{AH}[9,10]$. On the other hand, oxidative stress has been suggested as one of the major pathogenic factors causing 
increased resistance of AH outflow and elevated IOP in the POAG $[9,10]$, and the TM cell the most sensitive cell type to oxidant insults $[12,13]$. Therefore, it would be plausible to speculate that oxidative stress could increase outflow resistance and elevate IOP during the POAG by promoting excessive production of the ECM proteins in the TM.

Then it would be interesting to ascertain the molecular link between oxidative stress and excessive ECM production in TM cells. Hairy and enhancer of split-1 (HES1) is a transcriptional repressor that belongs to the basic helix-loop-helix family of transcription factors [14]. HES1 functions downstream Notch signaling pathway, determining cell fate during development of nervous [14] and digestive systems [16]. More importantly, HES1 expression is up-regulated during lung $[17,18]$ and kidney [19] fibrosis, indicating an association of this transcription factor with profibrotic ECM protein production. Therefore, we hypothesize that HES1 may promote profibrotic ECM protein expression in TM cells under oxidative stress, contributing to the increased $\mathrm{AH}$ outflow resistance and elevated IOP that ultimately lead to the POAG. To test this hypothesis, we subjected human TM cells (HTMCs), a primary cell culture commonly used in glaucoma research [20-23], to oxidative stress induced by a sublethal dose of $\mathrm{H}_{2} \mathrm{O}_{2}$. We found the upregulated expression of ECM and HES1 genes, as well as the compromised cell functions, such as migration and proliferation, in $\mathrm{H}_{2} \mathrm{O}_{2}$-stimulated HTMCs. Furthermore, our results demonstrated the requirement and sufficiency of HES1 up-regulation for the excessive ECM protein production and impaired cell functions in the HTMCs exposed to the oxidant, thereby providing a novel regulatory mechanism underlying the cell phenotypic changes caused by oxidative stress.

\section{RESULTS}

\section{$\mathrm{H}_{2} \mathrm{O}_{2}$-induced oxidative stress impaired HTMCs' viability}

To identify the effects of oxidative stress on cell viability, the HTMCs were subjected to different concentrations of $\mathrm{H}_{2} \mathrm{O}_{2}$ for $2 \mathrm{~h} . \mathrm{H}_{2} \mathrm{O}_{2}$ at 100, 200, 300, and $400 \mu \mathrm{M}$ reduced the cell viability progressively (Figure $1 \mathrm{~A}, p<0.01,200 \mu \mathrm{M} \mathrm{H}_{2} \mathrm{O}_{2}$ vs normal; $p<0.001,300$ or $400 \mu \mathrm{M} \mathrm{H}_{2} \mathrm{O}_{2}$ vs normal), with the cell viability ranging from $86.55 \pm 9.31 \%$ to $57.36 \pm 3.97 \%$ of the normal control. This suggests that $\mathrm{H}_{2} \mathrm{O}_{2}$, at lower concentrations, inhibits the viability of HTMCs in a dose-dependent manner (Figure 1A). Moreover, the cell viability was reduced to $28.07 \pm 3.95 \%$ of the normal control when the cells were exposed to $600 \mu \mathrm{M} \mathrm{H}_{2} \mathrm{O}_{2}$ (Figure 1A, $p$ $<0.001,600 \mu \mathrm{M} \mathrm{H}_{2} \mathrm{O}_{2}$ vs normal), however, it was not further compromised when $\mathrm{H}_{2} \mathrm{O}_{2}$ concentration increased to 800 and $1000 \mu \mathrm{M}$ (Figure 1A), indicating a limited dose dependency of the $\mathrm{H}_{2} \mathrm{O}_{2}$-induced inhibition on cell viability. A dose-responsive curve was plotted to more clearly reflect the inhibitory effects of $\mathrm{H}_{2} \mathrm{O}_{2}$ on the cell viability (Figure 1B). The IC50 for $\mathrm{H}_{2} \mathrm{O}_{2}$ approximated $300 \mu \mathrm{M}$ (Figure 1B). Since cell functions, including migration and proliferation, would be analyzed, the IC50 $\left(\mathrm{H}_{2} \mathrm{O}_{2}\right.$ at $\left.300 \mu \mathrm{M}\right)$ was used in the following experiments.

\section{Oxidative stress up-regulated ECM protein expression and impaired cell functions}

Treating the HTMCs with $300 \mu \mathrm{M} \mathrm{H}_{2} \mathrm{O}_{2}$ for $2 \mathrm{~h}$ significantly up-regulated the expression of profibrotic ECM proteins, including Fibronectin, Collagen I,
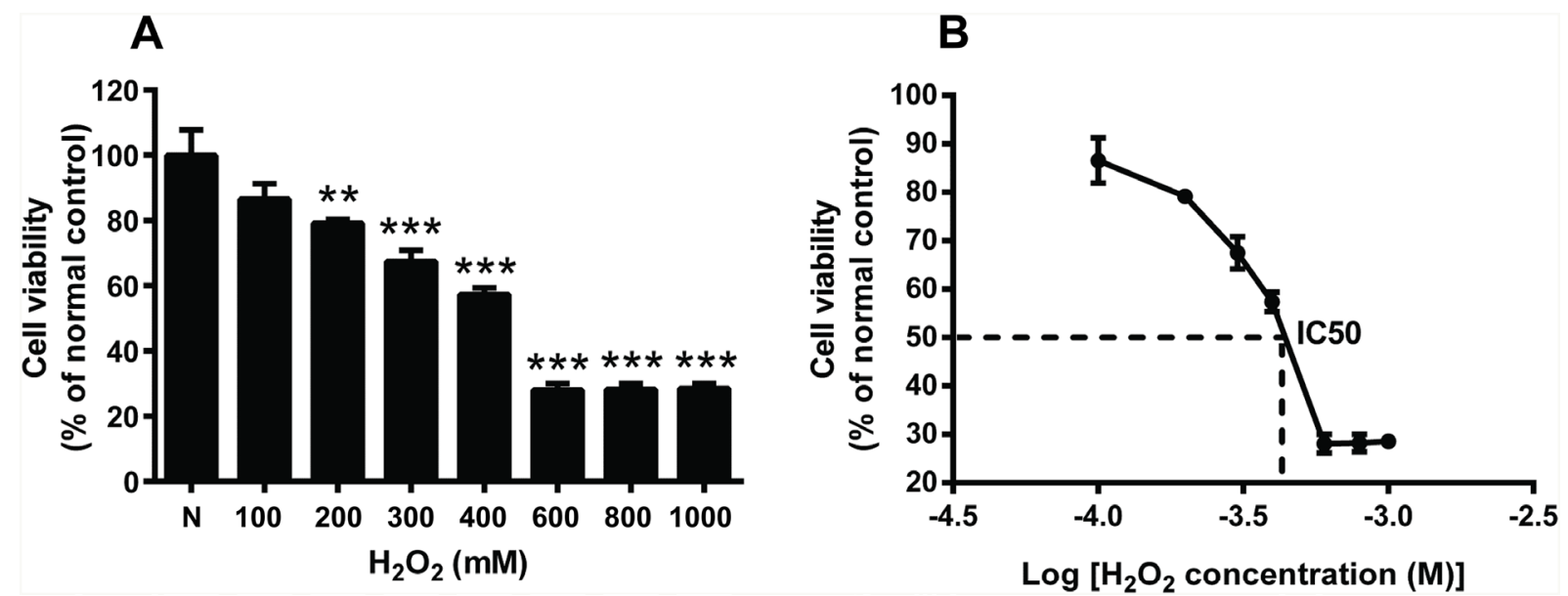

Figure 1: $\mathrm{H}_{2} \mathrm{O}_{2}$ at different concentrations induced oxidative stress and impaired the HTMC's viability. The HTMCs were exposed to a series of concentrations of $\mathrm{H}_{2} \mathrm{O}_{2}$ for $2 \mathrm{~h}$. The cell viability, expressed as percentage of normal control, was shown in (A), $\mathrm{N}$ stands for normal control. A dose responsive curve was plotted in (B), y-axis is the cell viability expressed as percentage of normal control, $\mathrm{x}$-axis is logarithm of $\mathrm{H}_{2} \mathrm{O}_{2}$ concentration. The $\mathrm{IC} 50$ for $\mathrm{H}_{2} \mathrm{O}_{2}$ is $300 \mu \mathrm{M}$. The data were presented as mean $\pm \mathrm{SEM}$ ( $\mathrm{n}=4$ for each concentration in each experiment, and each experiment was repeated 3 times; $* * p<0.01$, $* * * p<0.001$, as compared to normal control.) 
Laminin, and $\alpha$-SMA. As shown by western blots (Figure $2 \mathrm{~A}$ ), the relative protein levels of these ECM genes in the $\mathrm{H}_{2} \mathrm{O}_{2}$-treated cells were $1.81 \sim 3.03$ fold higher than the normal controls (Figure 2B, $\mathrm{H}_{2} \mathrm{O}_{2}$ vs normal, $p<0.01$ for Fibronectin, Laminin, and $\alpha$-SMA; $p<0.05$ for Collagen I). These results were consistent with previous studies $[23,24]$. The results of immunofluorescence revealed that the fluorescence intensities of the ECM proteins in the cytoplasm under oxidative stress were substantially greater than those under normal condition (Figure 2C2J). Additionally, the HTMCs were more spread-out, and exhibited a patchy shape under $\mathrm{H}_{2} \mathrm{O}_{2}$ treatment (Figure
$2 \mathrm{G}-2 \mathrm{~J})$, in contrast to a spindle-like shape observed in the normal control (Figure 2C-2F).

We also evaluated cell migration and proliferation functions following $2 \mathrm{~h}$-treatment of $\mathrm{H}_{2} \mathrm{O}_{2}$ (Figure 3 ). The cell migration was examined by a Transwell assay. The number of migrated cells was $343.00 \pm 46.38$ per well under normal condition, and reduced to $154.50 \pm 27.68$ pre well after $\mathrm{H}_{2} \mathrm{O}_{2}$ treatment, being only $45.04 \%$ of the normal control (Figure 3A-3E). On the other hand, the cell proliferation was first examined by a Cell Counting Kit-8 (CCK-8). The results showed that both the $\mathrm{H}_{2} \mathrm{O}_{2}$ treated HTMCs and the normal controls doubled their
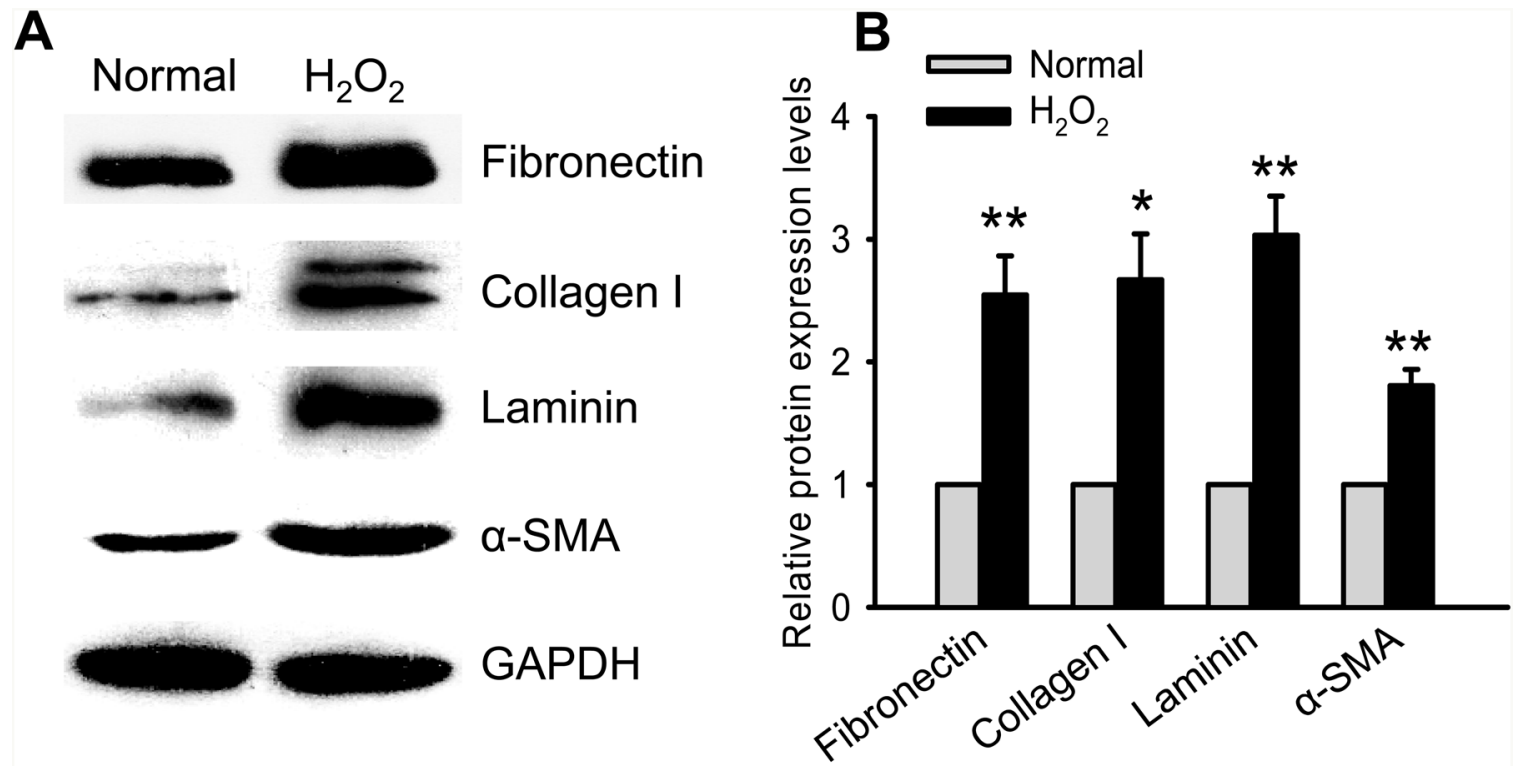

Fibronectin
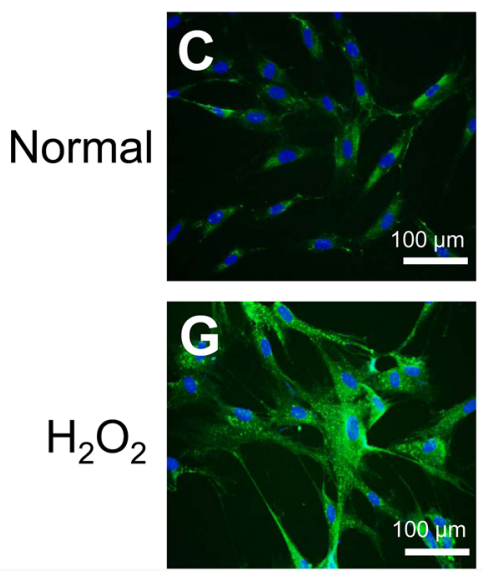

Collagen I
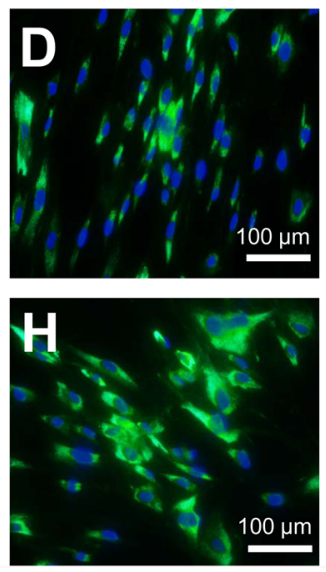

Laminin
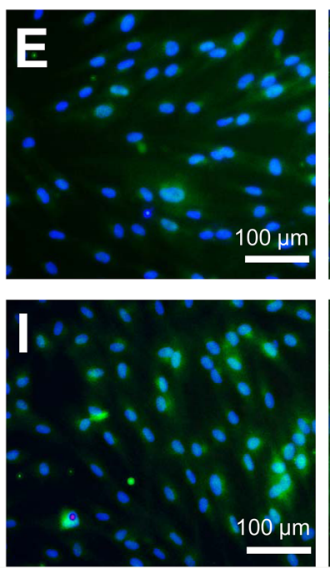

a-SMA
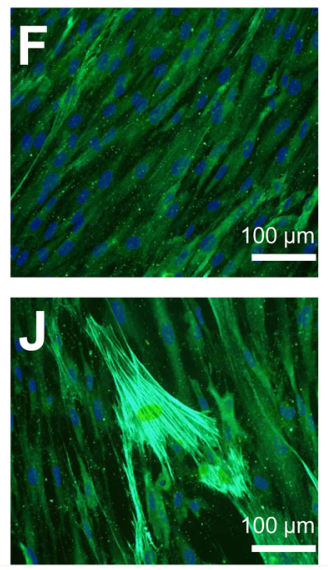

Figure 2: Oxidative stress promoted ECM protein expression. Representativewestern blots showed up-regulated expression of the ECM proteins, including Fibronectin, Collagen I, Laminin, and $\alpha-S M A$, in the HTMCs subjected to the $2 \mathrm{~h}_{\text {-treatment }}$ of $\mathrm{H}_{2} \mathrm{O}_{2}(\mathbf{A})$. The intensities of target protein bands were normalized to those of an internal standard, GAPDH, and the relative protein expression levels of the ECM genes were shown in (B). Immunofluorescence confirmed the trends of up-regulated expression and showed cytoplasmic accumulation of the ECM proteins in the HTMCs under oxidative stress (C-J). The data were presented as mean \pm SEM ( $n=3$ per group for each experiment, each experiment was repeated 3 times; $* p<0.05, * * p<0.01$, as compared to normal control). 

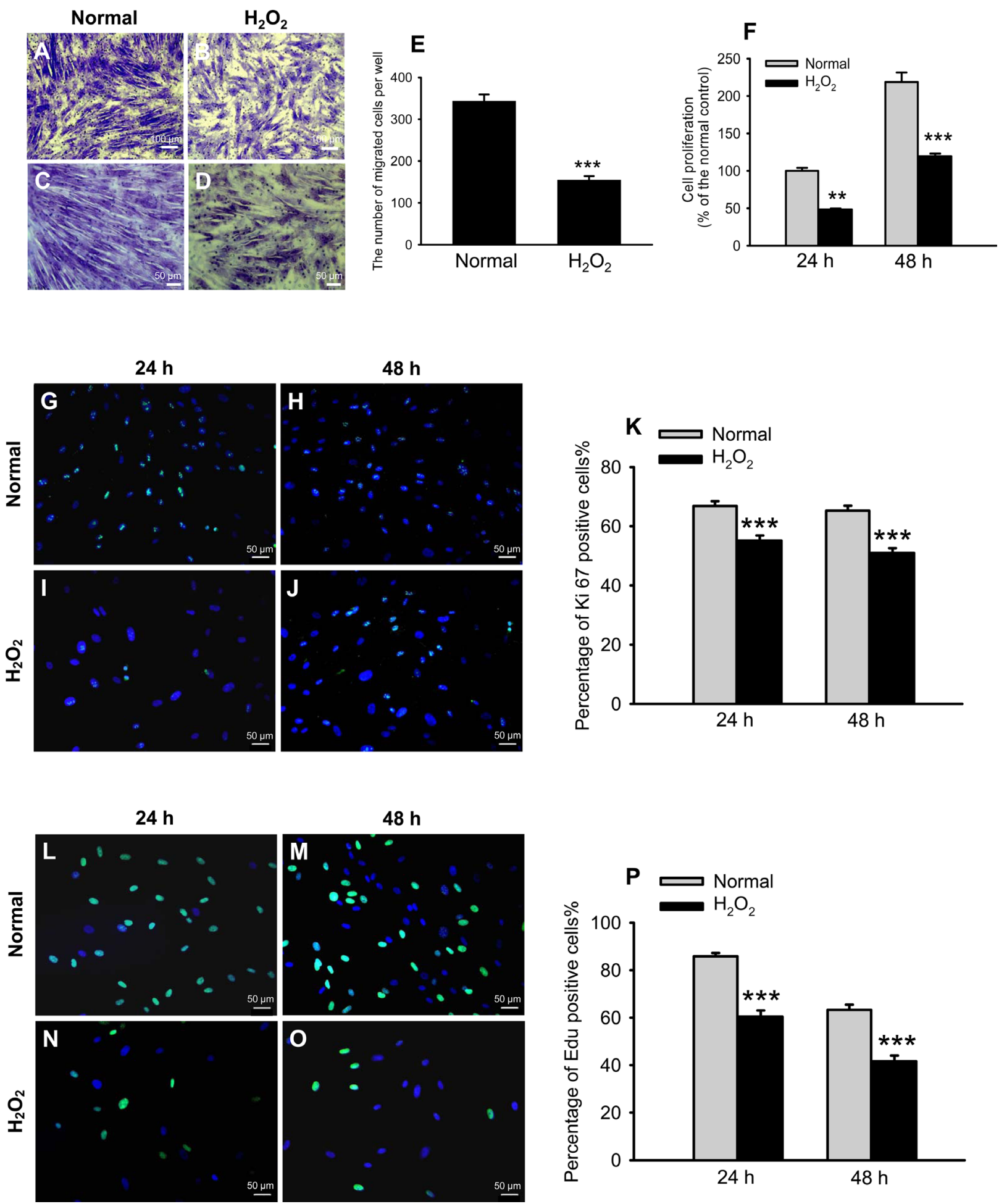

Figure 3: Oxidative stress impaired cell migration and proliferation. Representative pictures of cell migration under norm and oxidative stress were shown in (A-D), among which (A) and (B) are low magnification, (C) and (D) are high magnification. The migrated cells were quantified in (E). Cell proliferation at 24 and $48 \mathrm{~h}$ after $\mathrm{H}_{2} \mathrm{O}_{2}$ exposure was first measured by CCK-8 and expressed as percentage of the normal control (F). The effects of $\mathrm{H}_{2} \mathrm{O}_{2}$ on cell proliferation were confirmed by Ki67 staining and Edu assay. Representative pictures of Ki67 staining at 24 and 48 h post oxidative stress were shown in (G-J). The percentages of Ki67-positive cells at both time points were quantified in $\mathbf{( K )}$. Representative pictures of Edu assay were shown in $\mathbf{( L - O )}$. The percentages of Edu-positive cells were quantified in $(\mathbf{P})$. The data were presented as mean $\pm \operatorname{SEM}(\mathrm{n}=8 \sim 32$ per group for each experiment, each experiment was repeated 3 times; ** $p<0.01$, $* * * p<0.001$, as compared to normal control). 
population from 24 to $48 \mathrm{~h}$ post the oxidative stress (Figure 3F). However, at each time point, the $\mathrm{H}_{2} \mathrm{O}_{2}$ exposure did significantly impair the cells' proliferative ability, rendering the number of $\mathrm{H}_{2} \mathrm{O}_{2}$-treated cells only $48.48 \%$ and $54.60 \%$ of the normal control (Figure 3F, normal vs $\mathrm{H}_{2} \mathrm{O}_{2}, p<0.01$ for $24 \mathrm{~h} ; p<0.001$ for $48 \mathrm{~h}$ ). To confirm the effects of $\mathrm{H}_{2} \mathrm{O}_{2}$ on cell proliferation, the HTMCs were then subjected to Ki67 staining and 5-ethynyl-2'-deoxyuridine (Edu) assay, which label a proliferation-associating nuclear protein [25] and actively synthesizing DNA [26], respectively. Indeed, the results demonstrated that both $\mathrm{Ki} 67$ and Edu signals were colocalized with 4',6-diamidino-2-phenylindole (DAPI) staining (Figure 3G-3J and Figure 3L-3O), indicating their nuclear localizations. Importantly, in the $\mathrm{H}_{2} \mathrm{O}_{2}$-treated cells, the percentages of Ki67- and Edu-positive cells were both significantly lower than those in the normal controls at each time points (Figure $3 \mathrm{~K}$ and $3 \mathrm{P}$, normal vs $\mathrm{H}_{2} \mathrm{O}_{2}$, all $p<0.001$ ). The results of Ki67 (Figure $3 \mathrm{G}-3 \mathrm{~K}$ ) and Edu staining (Figure 3L-3P), the 2 widely used approaches for detecting proliferative cells, were similar to those of CCK8 (Figure 3F), therefore, CCK-8 was used in the following experiments to examine cell proliferation. Together, these results suggest that a transient oxidative exposure induces significant up-regulation and cytoplasmic accumulation of the profibrotic ECM proteins, and also generates relatively long-lasting inhibitory effects on migratory and proliferative functions in the HTMCs.

\section{Oxidative stress up-regulated HES1 expression at both transcript and protein levels}

We then examined the expression of a transcription factor HES1 by quantitative real-time PCR (qPCR), western blot, and immunofluorescence in the HTMCs treated with $\mathrm{H}_{2} \mathrm{O}_{2}$. The qPCR results showed that HES1 mRNA levels increased 1.92 fold following oxidative stress (Figure 4A, $p<0.01$, normal vs $\mathrm{H}_{2} \mathrm{O}_{2}$ ). Western blots showed that HES1 protein expression was boosted 2.55 fold by $\mathrm{H}_{2} \mathrm{O}_{2}$ treatment (Figure $4 \mathrm{~B}$ and $4 \mathrm{C}, p<$ 0.05 , normal vs $\mathrm{H}_{2} \mathrm{O}_{2}$ ). Immunofluorescence revealed a substantially greater fluorescence intensity of HES1 staining in the $\mathrm{H}_{2} \mathrm{O}_{2}$-treated cells than that in the normal controls (Figure 4D and 4G). Besides, HES1 staining colocalized with DAPI staining (Figure 4E and $4 \mathrm{H}$ ), which suggests a predominant nuclear localization of this transcription under both normal and oxidative conditions (Figure 4F and 4I). Moreover, $\mathrm{H}_{2} \mathrm{O}_{2}$ induced a comparable extent of HES1 up-regulation at protein level to that at mRNA level, suggesting that the expression of this gene is mainly, if not entirely, regulated at the transcriptional level. Together with the results of elevated ECM protein levels following $\mathrm{H}_{2} \mathrm{O}_{2}$ treatment (Figure 2), the up-regulation of HES1 implicates its possible role in promoting ECM expression in the HTMCs under oxidative stress.

\section{HES1 knockdown abrogated the up-regulated ECM protein expression under oxidative stress}

We then investigated whether HES1 knockdown could abrogate the $\mathrm{H}_{2} \mathrm{O}_{2}$-induced up-regulation of ECM protein expression in the HTMCs. Lentiviral particles carrying HES1 shRNA or a scrambled sequence were used to transduce the HTMCs. The cells were subjected to $\mathrm{H}_{2} \mathrm{O}_{2}$ treatment at $5 \mathrm{~d}$ after virus transduction. As expected, a significant up-regulation of HES1 gene expression after $\mathrm{H}_{2} \mathrm{O}_{2}$ exposure was detected by qPCR in the scrambletransduced cells (Figure 5A, $p<0.001$, scramble normal vs scramble $\mathrm{H}_{2} \mathrm{O}_{2}$ ). More importantly, in the shRNAtransduced cells, HES1 mRNA levels were reduced to $24.50 \%$ of those in the scramble-transduced cells under normal condition (Figure 5A, $p<0.01$, shRNA normal vs scramble normal); whereas the effects of shRNA were more dramatic under oxidative stress, with HES1 mRNA levels in the shRNA-transduced cells being merely $12.26 \%$ of those in the scramble-transduced cells (Figure 5A, $p$ $<0.001$, shRNA $\mathrm{H}_{2} \mathrm{O}_{2}$ vs scramble $\mathrm{H}_{2} \mathrm{O}_{2}$ ). HES1 protein expression exhibited a similar trend as shown by western blots (Figure 5B and 5C). These results confirmed an efficient knockdown of HES1 expression in the HTMCs at both basal and oxidative stress-induced levels.

Accordingly, under normal condition, there were $43 \% \sim 73 \%$ reductions in the expression levels of ECM proteins in the HES1 shRNA-transduced cells, as compared to the scramble-transduced cells (Figure 5D and $5 \mathrm{E}$ ), implicating that basal level expression of HES1 is required for maintaining normal ECM protein expression. Whereas under oxidative stress, the ECM proteins were up-regulated $3 \sim 4$ fold in the scramble-transduced cells as expected (Figure 5D and 5E, scramble normal vs scramble $\mathrm{H}_{2} \mathrm{O}_{2}, p<0.01$ for Fibronectin; $p<0.001$ for Laminin, Collagen I, and $\alpha$-SMA). Yet, lentivirus-mediated expression of HES1 shRNA significantly subdued the $\mathrm{H}_{2} \mathrm{O}_{2}$-induced up-regulation of Fibronectin protein (Figure 5D and 5E, $p<0.01$, shRNA $\mathrm{H}_{2} \mathrm{O}_{2}$ vs scramble $\mathrm{H}_{2} \mathrm{O}_{2}$ ), reversed that of Laminin protein (Figure 5D and $5 \mathrm{E}, p<0.001$, shRNA $\mathrm{H}_{2} \mathrm{O}_{2}$ vs scramble $\mathrm{H}_{2} \mathrm{O}_{2} ; p<0.01$, shRNA $\mathrm{H}_{2} \mathrm{O}_{2}$ vs scramble normal), and abrogated those of Collagen I and $\alpha$-SMA proteins (Figure 5D and $5 \mathrm{E}, p$ $<0.001$ for both ECM proteins, shRNA $\mathrm{H}_{2} \mathrm{O}_{2}$ vs scramble $\mathrm{H}_{2} \mathrm{O}_{2} ; p>0.05$ for both, shRNA $\mathrm{H}_{2} \mathrm{O}_{2}$ vs scramble normal). In addition, immunofluorescence staining confirmed the trends of protein expression changes detected by western blots, and revealed the cytoplasmic accumulation of these proteins (Figure 5F-5U). The results suggest that HES1 shRNA delivered by lentivirus can significantly reduce the expression of this transcription factor at both mRNA and protein levels, which inhibits or abolishes the upregulation of ECM proteins in the HTMCs exposed to oxidative stress. 


\section{HES1 knockdown partially rescued cell function defects under oxidative stress}

We next studied whether HES1 knockdown could ameliorate the cell function defects caused by oxidative stress. In the Transwell assay, the $2 \mathrm{~h}$-treatment of $\mathrm{H}_{2} \mathrm{O}_{2}$ greatly reduced the number of migrated cells in the scramble-transduced HTMCs (Figure 6A-6E, $p<0.001$, scramble normal vs scramble $\mathrm{H}_{2} \mathrm{O}_{2}$ ). Whereas knocking down HES1 expression by its shRNA significantly enhanced the cell's migratory ability under both normal and oxidative conditions (Figure 6A-6E, $p<0.001$, shRNA normal vs scramble normal; $p<0.05$, shRNA $\mathrm{H}_{2} \mathrm{O}_{2}$ vs scramble $\mathrm{H}_{2} \mathrm{O}_{2}$ ), however, the number of migrated cells in the shRNA-transduced HTMCs under oxidative stress was still significantly less than the normal control
(Figure 6A-6E, $p<0.001$, shRNA $\mathrm{H}_{2} \mathrm{O}_{2}$ vs scramble normal), indicating a partial rescue of cell migration by HES1 shRNA and involvement of additional regulators. Moreover, cell proliferation exhibited a similar trend. Knocking down HES1 expression significantly promoted cell proliferation at both 24 and $48 \mathrm{~h}$ after $\mathrm{H}_{2} \mathrm{O}_{2}$ treatment (Figure 5F, $p<0.05$ for both time points, shRNA $\mathrm{H}_{2} \mathrm{O}_{2}$ vs scramble $\mathrm{H}_{2} \mathrm{O}_{2}$ ). It was notable that at $48 \mathrm{~h}$ following the oxidative episode, the number of shRNA-treated cells was comparable to the normal controls (Figure $6 \mathrm{~F}, p>$ 0.05 , shRNA $\mathrm{H}_{2} \mathrm{O}_{2}$ vs scramble normal), suggesting that down-regulating HES1 expression could restore the cell proliferative function during a prolonged period. The results of cell migration and proliferation assays indicate that HES1 up-regulation is required for the oxidative stress-induced cell function defects.
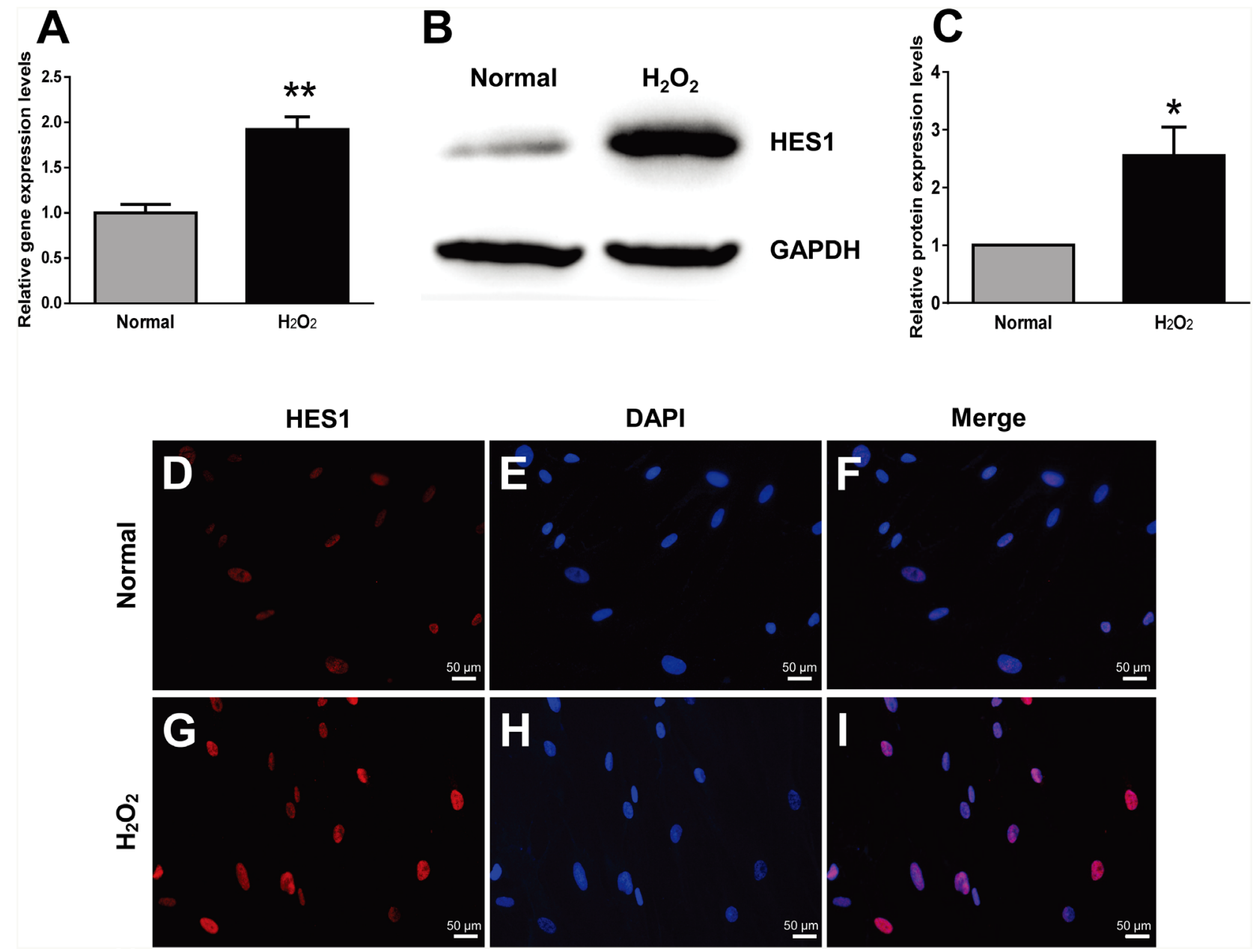

Figure 4: HES1 expression was up-regulated at both mRNA and protein levels in HTMCs under oxidative stress. The qPCR showed an enhanced HES1 expression at mRNA levels in HTMCs subjected to the 2 h-treatment of $\mathrm{H}_{2} \mathrm{O}_{2}(\mathbf{A})$. Representative western blots showed an increased protein expression of HES1 induced by the 2 h-oxidative stress (B). The intensities of HES1 protein bands were normalized to those of the internal standard GAPDH, and the relative HES1 protein expression levels were shown in (C). HES1 immunostaining confirmed the trend of its expression changes under norm (D) and oxidative stress (G). The cell nuclei under both conditions were stained with DAPI $(\mathbf{E}$ and $\mathbf{H})$. The HES1 staining was colocalized with DAPI staining $(\mathbf{F}$ and $\mathbf{I})$. The data were presented as mean \pm SEM $\left(n=3\right.$ per group for each experiment, each experiment was repeated 3 times; ${ }^{*} p<0.05, * * p<0.01$, as compared with normal control). 


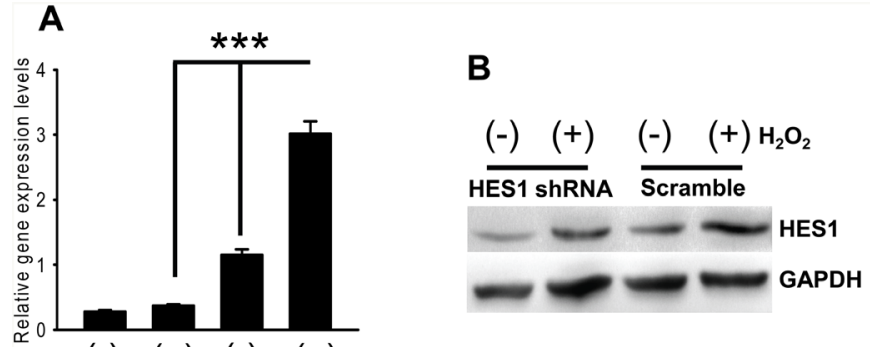

$\begin{array}{llll}(-) & (+) & (-) & (+) \\ \mathrm{H}_{2} \mathrm{O}_{2}\end{array}$ HES1 shRNA Scramble

D

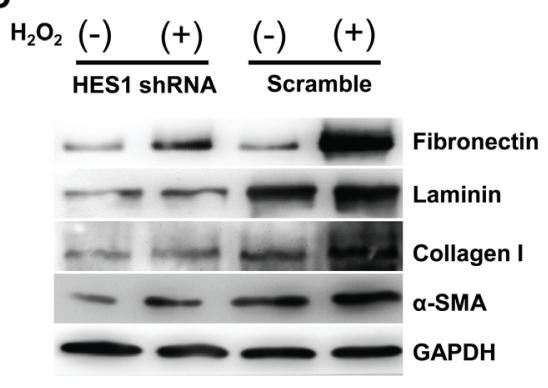

$(-)$

$(+)$

HES1 ShRNA
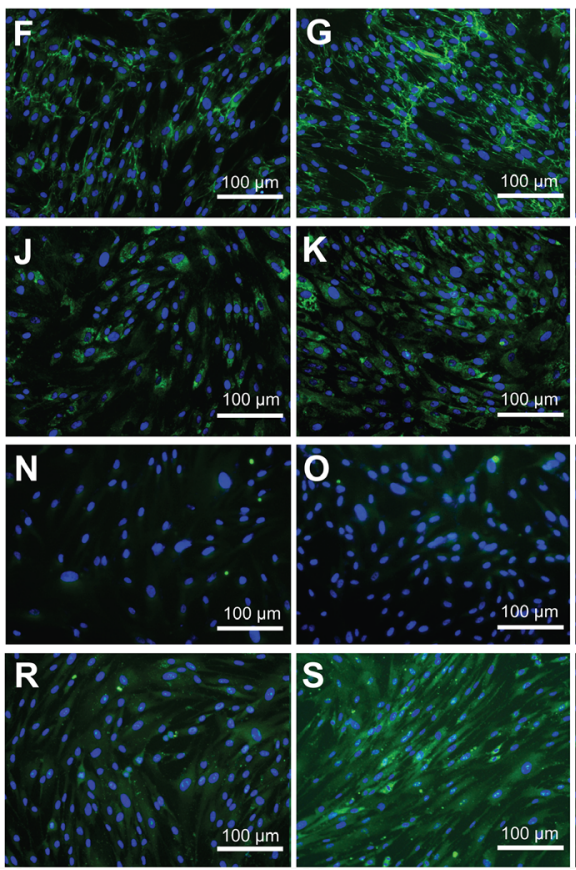

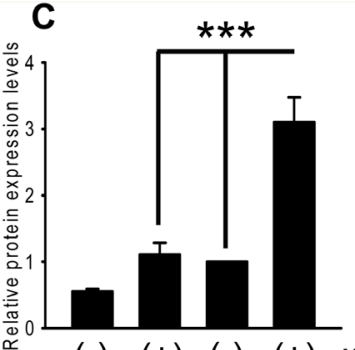

$(-) \quad(+) \quad(-) \quad(+) \quad \mathrm{H}_{2} \mathrm{O}_{2}$

HES1 shRNA Scramble

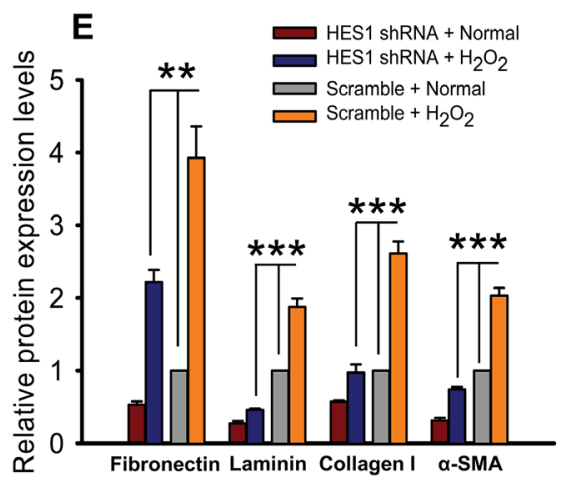

$(-)$

$(+)$

$\mathrm{H}_{2} \mathrm{O}_{2}$

Scramble
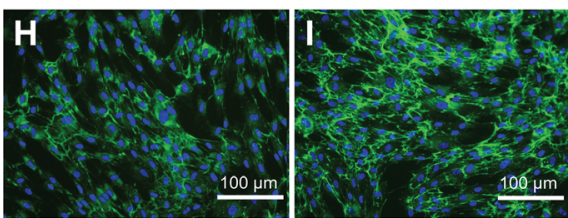

Fibronectin
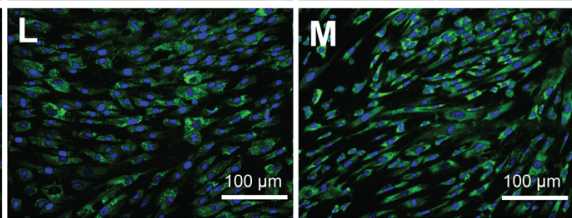

Collagen I
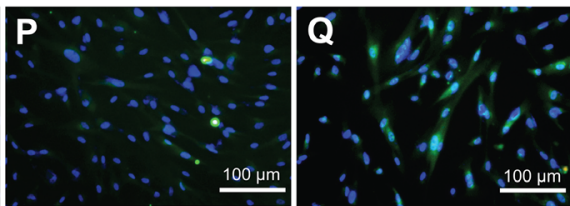

Laminin
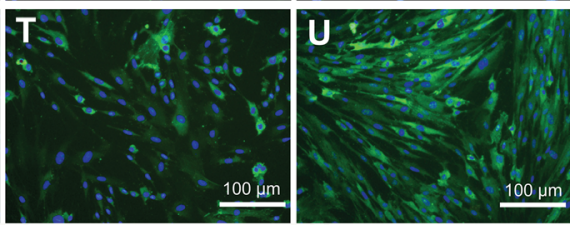

a-SMA

Figure 5: HES1 knockdown abrogated the up-regulation of ECM proteins in the HTMCs under oxidative stress. HES1 shRNA efficiently knocked down HES1 expression at the transcript levels, as shown by qPCR, in the HTMCs under normal and oxidative stress conditions (A). Western blots (B) and their quantification (C) showed the down-regulation of HES1 protein expression by HES1 shRNA in the HTMCs under both norm and oxidative stress. Western blots (D) revealed that the up-regulation of ECM proteins under oxidative stress was subdued (for Fibronectin), reversed (for Laminin), or abolished (for Collagen I and $\alpha$-SMA) by HES1 shRNA (E). Immunofluorescence confirmed the trends of ECM protein expression changes under both normal and oxidative conditions in the HES1 shRNA-transduced HTMCs (F-U). The data were presented as mean \pm SEM ( $n=3$ per group for each experiment, each experiment was repeated 3 times, $* * p<0.01, * * * p<0.001)$. 


\section{HES1 overexpression generated the molecular and functional effects similar to oxidative stress}

The HTMCs were transduced with a lentivirus carrying HES1 cDNA. At $5 \mathrm{~d}$ post virus transduction, the mRNA and protein levels of this transcription factor were up-regulated 6.55 and 7.81 fold, as shown by qPCR and western blots, respectively (Figure 7A-7C, lenti-HES1 vs lenti-vector, $p<0.001$ for mRNA levels; $p<0.01$ for protein levels), confirming an overexpression of HES1 gene in the HTMCs. The HES1 overexpression resulted in $2.57 \sim 3.27$ fold up-regulation of the profibrotic ECM proteins (Figure 7D and 7E, lenti-HES1 vs lenti-vector, $p$ $<0.01$ for Fibronectin and Laminin; $p<0.05$ for Collagen I; $p<0.001$ for $\alpha$-SMA), and the up-regulated trends were corroborated by immunofluorescence (Figure 7F-7M).

Furthermore, the HTMCs overexpressing HES1 exhibited significantly diminished migration and proliferation, as compared to the empty vector-transduced cells (Figure 8, lenti-HES1 vs lenti-vector, $p<0.05$ for Transwell; $p<0.01$ for CCK at $24 \mathrm{~h} ; p<0.05$ for CCK at $48 \mathrm{~h}$ ). The effects of HES1 overexpression on ECM protein expression and cell functions resembled those produced by $\mathrm{H}_{2} \mathrm{O}_{2}$, suggesting that HES1 up-regulation is sufficient to elicit the cell phenotypic changes in ECM protein expression and cell functions as seen under oxidative stress.

\section{DISCUSSION}

$\mathrm{H}_{2} \mathrm{O}_{2}$ is a key source of oxidant and natural constituent of AH in human eyes. The concentrations of $\mathrm{H}_{2} \mathrm{O}_{2}$ in $\mathrm{AH}$ of normal and cataractous eyes are 25 and 69 $\mu \mathrm{M}$, respectively [27]. Nonetheless, it has been reported that patients with POAG have significantly elevated oxidative levels and reduced anti-oxidative capacity in $\mathrm{AH}$ as compared with cataract patients [28]. This implicates that TM cells in glaucomatous eyes might be exposed to $\mathrm{H}_{2} \mathrm{O}_{2}$ at higher concentration than that in cataract eyes, i.e. $69 \mu \mathrm{M}$. Whereas in the experimental studies, $\mathrm{H}_{2} \mathrm{O}_{2}$ at the concentrations ranging from 100 to $800 \mu \mathrm{M}$ has been applied to the HTMCs to induce oxidative stress,

\section{$(-)$}

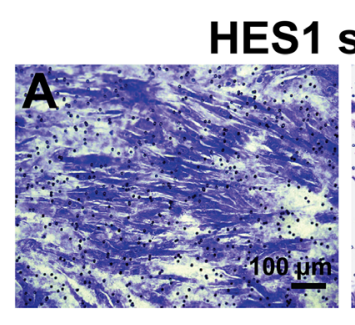

$(+)$

$(-)$

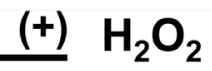

\section{Scramble}
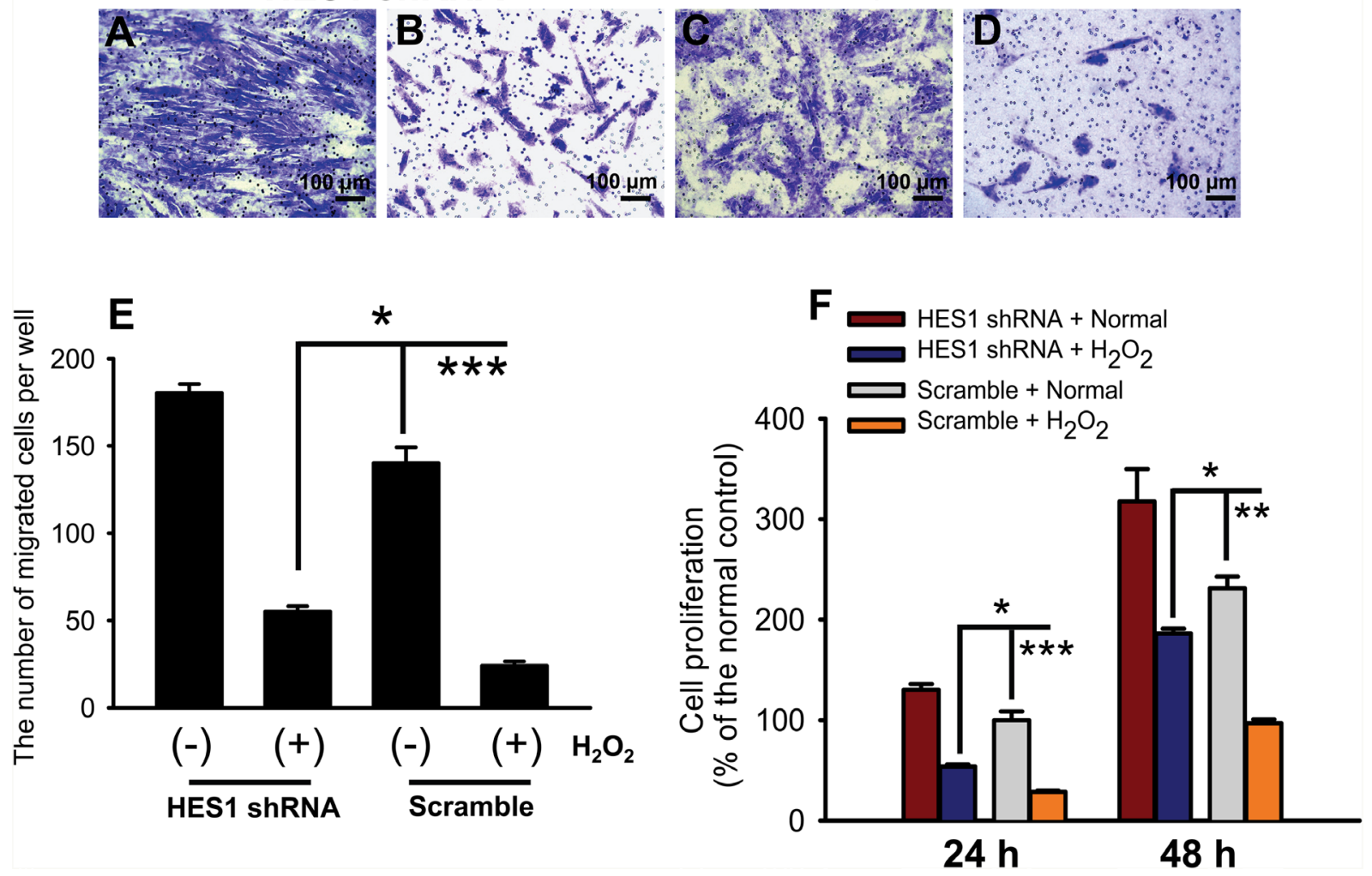

Figure 6: HES1 knockdown partially recovered cell functions under oxidative stress. The representative pictures of cell migration were shown in (A-D) under both normal and oxidative stress conditions following HES1 shRNA transduction. HES1 shRNA partially recovered the impaired cell migration capacity caused by the $2 \mathrm{~h}$-exposure to oxidative stress (E). The diminished cell proliferation caused by the $2 \mathrm{~h}$-treatment of $\mathrm{H}_{2} \mathrm{O}_{2}$ was partially (at $24 \mathrm{~h}$ following oxidative stress) or completely (at $48 \mathrm{~h}$ following oxidative stress) restored by HES1 shRNA transduction $(\mathbf{F})$. The data were presented as mean \pm SEM $(\mathrm{n}=3 \sim 10$ per group for each experiment, each experiment was repeated 3 times; $* p<0.05, * * p<0.01, * * * p<0.001)$. 
serving as an in vitro pathological model for glaucoma research $[23,29,30]$. Therefore, in this study, $\mathrm{H}_{2} \mathrm{O}_{2}$ at the concentrations of 100, 200, 300, 400, 600, 800, and 1000 $\mu \mathrm{M}$ was transiently applied to the HTMC cultures, and cell viability was examined (Figure 1). An IC50 of $\mathrm{H}_{2} \mathrm{O}_{2}$ at 300 $\mu \mathrm{M}$ was selected to avoid massive cell death and loss of function caused by an overdose.

The up-regulation of the ECM proteins in the HTMCs upon an acute exposure to oxidative stress (Figure $2 \mathrm{~A}$ and $2 \mathrm{~B}$ ) was consistent with the studies conducted by us [23] and others [24, 31]. The increased production and cytoplasmic accumulation of the ECM proteins (Figure
$2 \mathrm{C}-2 \mathrm{~J})$ will likely result in an increased deposition of key ECM components, such as fibronectin, collagen I, and laminin, in TM. The excessive ECM deposition has been shown to remarkably alter TM microenvironment, resulting in an increased $\mathrm{AH}$ outflow resistance and elevated IOP as occurred in the POAG $[9,32,33]$.

It has been reported that HES1 up-regulation under oxidative stress contributes to pathogenesis of multiple diseases, including endothelial cell injury in atherosclerosis and hypertension [34], neuronal cell apoptosis in Alzheimer's disease [35], and myocardial damage following ischemia and reperfusion [36].
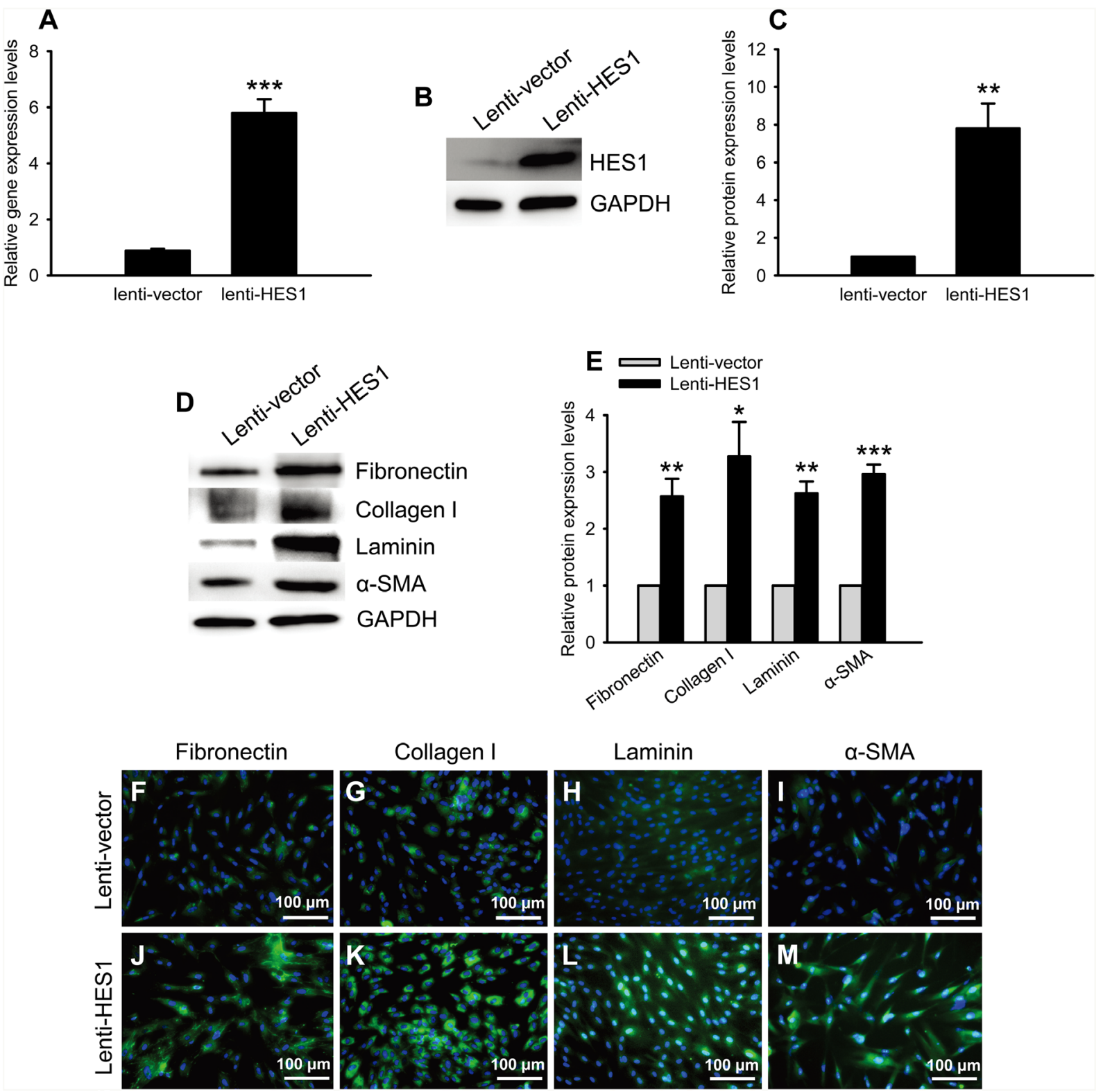

Figure 7: HES1 overexpression boosted expression of the ECM proteins. The qPCR (A) and western blots (B, C) showed an augmented expression of HES1 at mRNA and protein levels, respectively, in the HTMCs transduced by the lentivirus carrying human HES1 cDNA. Representative western blots of the ECM proteins were shown in (D). The western blot quantification showed the significant up-regulation of the ECM proteins (E). Immunofluorescence confirmed the increased expression of the ECM proteins induced by HES1 overexpression (F-M). 
Therefore, the enhanced HES1 expression in the HTMCs exposed to the transient oxidative stress (Figure 4) might unveil the pathogenic mechanism underlying the POAG. In addition, our results showed that the profibrotic ECM protein expression was up-regulated in the $\mathrm{H}_{2} \mathrm{O}_{2}$-treated HTMCs (Figure 2); knocking down HES1 expression by shRNA dramatically reduced the levels of these ECM proteins under both basal and oxidative conditions (Figure 5); and HES1 overexpression generated the opposite effects (Figure 7). These results, to our knowledge, are the first evidence showing HES1's regulation on profibrotic ECM protein expression in the HTMCs under oxidative stress. The results also indicate HES1 as a possible therapeutic target to the POAG.

Furthermore, the transient exposure to oxidative stress impaired the important functions of HTMCs, including proliferation and migration (Figure 3). TM cells are indispensible components of $\mathrm{AH}$ outflow facility; whereas dwindling in TM cells causes an inadequate lining along outflow pathway and consequently the decreased AH outflow [13]. Additionally, each TM cell contains anti-oxidant defense machinery, TM's scavenging capacity deteriorates as its cell population shrinks [37], rendering TM cells more susceptible to oxidative insults. Both scenarios eventually lead to the elevated IOP and POAG [13]. By contrast, the relationship between HTMC migration and IOP elevation is less clear. However, it has been reported that a specific inhibitor of Rho-associated coiled coil-forming protein kinase, Y-27632, with a capacity of lowering IOP and increasing $\mathrm{AH}$ outflow in rabbits [38], promotes HTMC migration in a dosedependent manner [39]. On the contrary, glucocorticoid, a drug known to reduce $\mathrm{AH}$ outflow, elevate the IOP, and induce secondary glaucoma, inhibits migration of HTMCs [40]. These reports suggest that there is at least an association, if not a causal relationship, between decreased cell migration and elevated IOP. Thus far, the diminished proliferative and migratory functions caused by the transient oxidative stress, together with the upregulated ECM protein expression, may all contribute to IOP elevation and POAG incidence. Moreover, HES1 shRNA administration abrogated the ECM up-regulation and ameliorated the functional defects (Figure 5 and 6), thereby implicating a novel and effective therapeutic modality to the POAG that warrants further development.

Nonetheless, one of the limitations of this study is that the molecular mechanism remains not completely clear on how HES1 promotes the profibrotic ECM protein expression in the oxidative stress-treated HTMCs. One possibility could be that as a transcriptional repressor [14], HES1 may act on a negative regulator of the ECM gene expression, thereby de-repressing the ECM protein
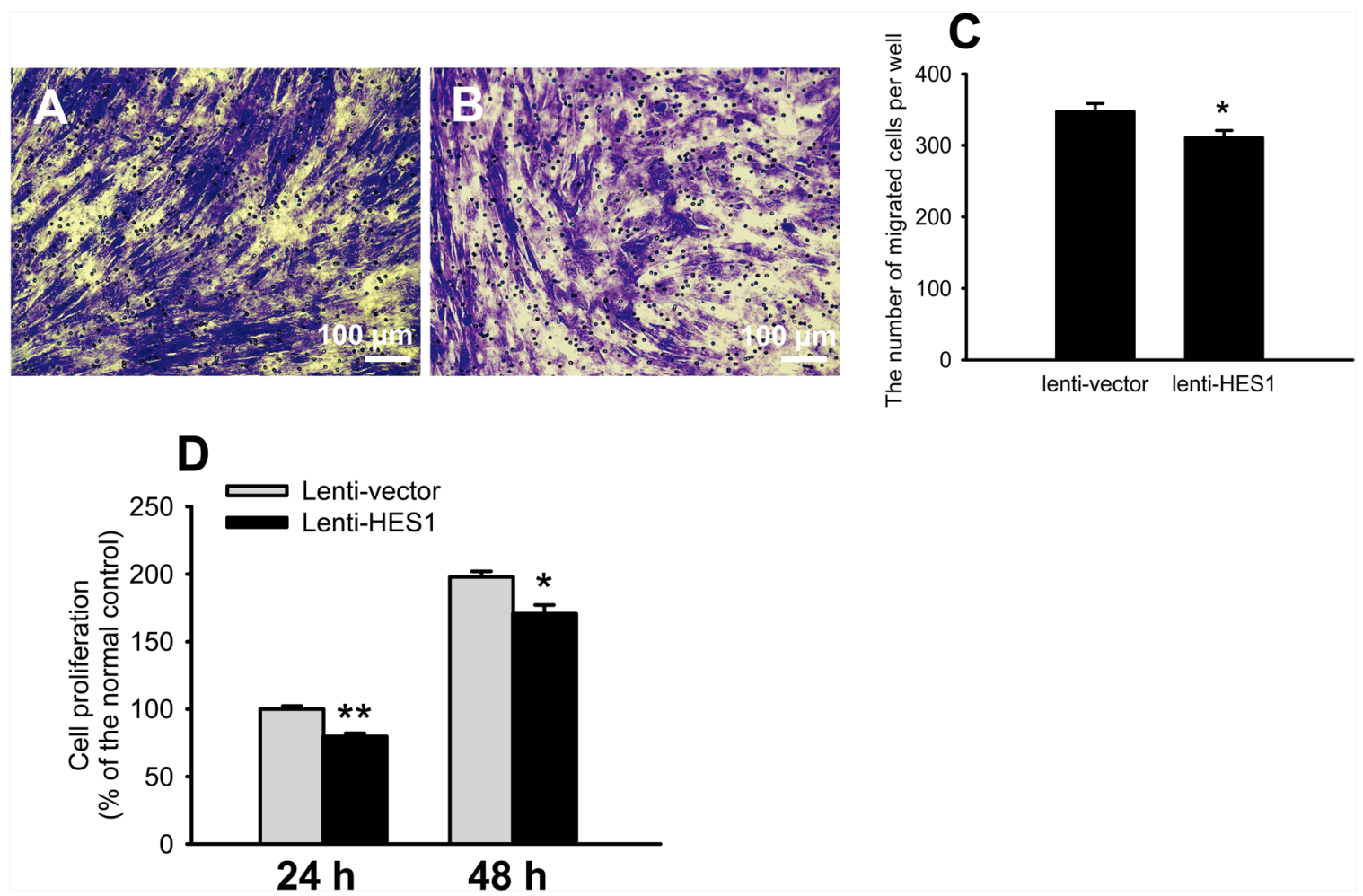

Figure 8: HES1 overexpression impaired the cell migratory and proliferative functions. Representative pictures of cell migration were shown in (A) and (B). Quantification showed that cell migration was reduced by overexpressing HES1 (C). Cell proliferation was compromised at both 24 and $48 \mathrm{~h}$ following HES1 overexpression (D). The data were presented as mean $\pm \operatorname{SEM}(\mathrm{n}=3 \sim 10$ per group for each experiment, each experiment was repeated 3 times, $* p<0.05, * * p<0.01$ ). 
Table 1: List of oligonucleotides in this study

\begin{tabular}{lll}
\hline Genes & Purposes & Sequences \\
\hline GAPDH-F & qPCR primer & 5'-CGAGATCCCTCCAAAATCAA-3' \\
GAPDH-R & qPCR primer & 5'-GTCTTCTGGGTGGCAGTGAT-3' \\
HES1-F & qPCR primer & 5'-TCAACACGACACCGGATAAA-3' \\
HES1-R & qPCR primer & 5'-CCGCGAGCTATCTTTCTTCA-3' \\
Pac-F & qPCR primer & 5'-CGAGTACAAGCCCACGGT-3' \\
Pac-R & qPCR primer & 5'-GTTCTTGCAGCTCGGTGAC-3' \\
RPPH1-F & qPCR primer & 5'-GCGGATGCCTCCTTTGC-3' \\
RPPH1-R & qPCR primer & 5'-ACCTCACCTCAGCCATTGAACT-3' \\
HES1-F & Expression primer & 5'-GCTCTAGAGCAATGCCAGCTGATATAATG-3' \\
HES1-R & 5'-GGAATTCCCCTCAGTTCCGCCACGGCCT-3' \\
HES1 & Expression primer & 5'-GAGCACAGAAAGTCATCAAAG-3' \\
\hline
\end{tabular}

expression. Alternatively, as a signaling molecule in Notch pathway, HES1 might interact with other signaling molecules [41, 42], the resulting interaction or protein complex might activate the expression of ECM proteins in this particular type of cells under oxidative stress. Therefore, it would be interesting to employ RNA sequencing or mass spectrometry technology in future experiments to search for the downstream target or protein binding partner of HES1. Then it would also be important to prove HES1 target and the proposed molecular mechanism in an animal model of experimental glaucoma, such as the rat model induced by laser photocoagulation on TM.

In summary, the current study for first time showed that HES1 promotes the profibrotic ECM protein expression and inhibits proliferative and migratory functions in the HTMCs under oxidative stress. This study suggests a novel regulatory mechanism connecting oxidative stress with HTMC phenotypic changes at molecular and functional levels, and also hints on a therapeutic target to the POAG.

\section{MATERIALS AND METHODS}

\section{Cell cultures}

All experimental procedures were approved by the Laboratory Animal Care and Use Committee of Tianjin Medical University (Permit Number: SYXK 2009-0001) and in accordance with the Association for Research in Vision and Ophthalmology Statement for the Use of Animals in Ophthalmic and Vision Research. The HTMCs, the primary cell culture isolated from the juxtacanalicular and corneoscleral regions of human eye, were purchased from Sciencell Research Laboratories (San Diego, CA, USA). The detailed information of the
HTMCs can be seen at https://www.sciencellonline.com/ human-trabecular-meshwork-cells.html\#product_tabs review_tabbed. The cells were maintained in the complete culture media composed of Dulbecco's Modified Eagle Medium (DMEM, $4.5 \mathrm{~g} / \mathrm{L}$ glucose, Life Technologies, Grand Island, NY, USA), 10\% Fetal Bovine Serum (FBS, Life Technologies, Grand Island, NY, USA), $100 \mathrm{U} / \mathrm{ml}$ penicillin $/ 100 \mu \mathrm{g} / \mathrm{ml}$ streptomycin (Life Technologies, Grand Island, NY, USA), and $2 \mathrm{mM}$ L-glutamine (Life Technologies, Grand Island, NY, USA) at $37{ }^{\circ} \mathrm{C}$ and $5 \% \mathrm{CO}_{2}$ in a cell culture incubator (Thermo Scientific, Waltham, MA, USA).

\section{Oxidative stress}

The HTMCs were seeded in a 96-well plate $\left(8 \times 10^{3}\right.$ cells / well) and cultured in plain DMEM ( $4.5 \mathrm{~g} / \mathrm{L}$ glucose, Life Technologies, Grand Island, NY, USA) for $24 \mathrm{~h}$ at $37{ }^{\circ} \mathrm{C}$. The cells were treated with DMEM containing $100,200,300,400,600,800$, and $1000 \mu \mathrm{M} \mathrm{H}_{2} \mathrm{O}_{2}$ for $2 \mathrm{~h}$. The cells treated with plain DMEM were included as the normal control. Then the media were replaced with $100 \mu \mathrm{l}$ DMEM containing $10 \mu \mathrm{l}$ CCK-8 reagent (Dojindo Laboratories, Kumamoto, Japan). The cells were incubated with CCK- 8 reagent at $37^{\circ} \mathrm{C}$ for $2 \mathrm{~h}$. The absorbance at $450 \mathrm{~nm}$ (A450) was measured by a Tecan Infinite M200 multimode microplate reader (Tecan Group Ltd., Männedorf, Switzerland). The cell viability was expressed as percentage of normal control.

\section{RNA isolation and quantitative real-time PCR}

Total RNA of the HTMCs was extracted by Trizol reagent (Life Technologies, Grand Island, NY, USA). The concentration and purity of total RNA were examined by a Nanodrop 2000 (Thermo Scientific, Waltham, MA, 
USA). After thorough digestion with DNase I (Thermo Scientific, Waltham, MA, USA), $1 \mu \mathrm{g}$ of total RNA was reverse transcribed using random hexamer primers in a Transcriptor First Strand cDNA Synthesis Kit (Roche, Basel, Switzerland) according to the manufacturer's protocol.

The qPCR was performed in triplicate in a 10 $\mu \mathrm{l}$ mixture containing cDNA template, gene-specific primers (Table 1), and iTaq Universal SYBR Green Supermix (Roche, Basel, Switzerland) in a 7500 Fast Real-time PCR System (Applied Biosystems, Waltham, MA, USA). The cDNA content of each target gene was normalized to internal standard GAPDH gene. The serially diluted pooled cDNA samples were used as templates to generate a standard curve between $\mathrm{Ct}$ values of each gene and logarithm of cDNA template concentrations. The standard curves served as positive controls for qPCR, and suggested similar priming efficiency between each target gene and GAPDH gene. The reactions using water as template served as negative controls for qPCR. The PCR program consisted of an initial cycle of $95^{\circ} \mathrm{C}$ for $10 \mathrm{~min}$ followed by 40 cycles of $95^{\circ} \mathrm{C}$ for $30 \mathrm{~s}$ and $60^{\circ} \mathrm{C}$ for 1 min. A dissociation stage was added to examine amplicon specificity. The relative expression levels of target genes were analyzed using a comparative threshold cycle $\left(2^{-\Delta \Delta \mathrm{Ct}}\right)$ method.

\section{Plasmid construction}

The shRNA against human HES1 gene (Table 1) was designed using web-based software at http://rnaidesigner. thermofisher.com/rnaiexpress. A scramble sequence (Addgene, Cambridge, MA, USA) was selected as a negative control. Both oligonucleotides were synthesized by Beijing Genomics Institute (Beijing, China), cloned into pLKO.1-puro shRNA vector (Addgene, Cambridge, MA, USA) via restriction endonuclease sites Age1 and EcoR1. The recombinant vectors were termed as pLKO.1HES1 shRNA and pLKO.1-scramble.

The cDNA of HES1 gene was amplified by PCR using a commercially available plasmid (Addgene, Cambridge, MA, USA) as template. The PCR product was cloned into the pCDH-CMV-MCS-EF1 $\alpha$-puro lentiviral vector (Addgene, Cambridge, MA, USA) through Xhol and EcoR1 sites. The resulting vector was designated as lenti-HES1. The empty vector was termed as lenti-vector and subserved a negative control.

\section{Lentivirus packaging, tittering, and transduction of HTMCs}

The lentivirus was packaged and tittered as previously described [43] with modifications. Briefly, 293FT cells were seeded into 6-well plates at a density of $6 \times 10^{5}$ cells / well, and cultured for $24 \mathrm{~h}$ before transfection. The 293FT cells were co-transfected with
$2 \mu \mathrm{g}$ lentiviral expression vector lenti-HES1, or lentivector, or pLKO.1-HES1 shRNA, or pLKO.1-scramble, $1.5 \mu \mathrm{g}$ pPAX2 packaging plasmid, and $0.5 \mu \mathrm{g}$ pVSVG envelope plasmid with assistance of $10 \mu \mathrm{l}$ lipofectamine 2000 transfection reagent (Life Technologies, Grand Island, NY, USA). The culture media were replaced at 6 $\mathrm{h}$ post transfection. At $48 \mathrm{~h}$ after transfection, the culture media were collected and centrifuged at 1,500 rpm at room temperature for $10 \mathrm{~min}$. The viral particle-containing supernatants (unconcentrated virus) were aliquoted and stored at $-80{ }^{\circ} \mathrm{C}$.

To measure the titers of packaged viruses, 293T cells seeded in a 6-well plate with a density of $8 \times 10^{5}$ cells / well were transduced with 1,10 , and $100 \mu$ of each unconcentrated virus with assistance of polybrene. At 64 $h$ post transduction, DNase I (Thermo Scientific, Waltham, MA, USA) was applied to culture media to remove the possible residual plasmids from virus packaging. The cells were rinsed with pre-warmed phosphate buffer saline (PBS) twice. The genomic DNA of transduced cells was extracted by a GeneJET Genomic DNA Purification Kit (Thermo Scientific, Waltham, MA, USA), after which RNase (Thermo Scientific, Waltham, MA, USA) was used to eliminate RNA contamination. The concentration and purity of genomic DNA were examined by a Nanodrop 2000 (Thermo Scientific, Waltham, MA, USA). Then 100 ng genomic DNA was used as template of qPCR. The copy number of puromycin resistance gene (puromycin$\mathrm{N}$-acetyltransferase gene, pac) on the lentiviral vector represents the copy number of the viruses integrated into genome; whereas Ribonuclease P RNA component H1 gene (RPPH1) served as an endogenous reference that has 2 copies in each diploid cell of human origin. The primers of both genes were listed in Table 1. The copy number of pac gene was normalized to that of RPPH1 gene. The qPCR was performed as described above. The titer was calculated as the averaged number of cells that can be transduced by $1 \mathrm{ml}$ virus. The viral titers were pLKO.1-HES1 shRNA, 6.58X107 integration unit (IU)/ $\mathrm{ml}$; pLKO.1-scramble, $1.17 \times 10^{8} \mathrm{IU} / \mathrm{ml}$; Lenti-HES1, 9.15X10 $\mathrm{IU} / \mathrm{ml}$; Lenti-vector, $1.26 \times 10^{8} \mathrm{IU} / \mathrm{ml}$.

The HTMCs were seeded in 24-well plates at a density of $2 \times 10^{5}$ cells / well. The cells were transduced by the viruses with equally-adjusted titers in presence of polybrene. The media were replaced with fresh complete culture media at $20 \mathrm{~h}$ post transduction. The subsequent analyses, including gene expression and cell function assays, were conducted at $5 \mathrm{~d}$ following viral transduction.

\section{Western blots}

Following the $2 \mathrm{~h}-\mathrm{H}_{2} \mathrm{O}_{2}$ treatment, the HTMCs were washed with pre-chilled PBS and harvested on ice. Total protein was extracted using a lysis buffer ( $\mathrm{pH}$ 6.8, CWBIO, Beijing, China) supplemented with $5 \% \beta$-mercaptoethanol (Sigma-Aldrich, St. Louis, MO, USA). Protein 
concentration was determined using a Bicinchoninic Acid Protein Assay Kit (CWBIO, Beijing, China). Western blots were preformed as previously described [44]. Briefly, $50 \mu \mathrm{g}$ protein samples were denatured at $100{ }^{\circ} \mathrm{C}$ for 10 min, separated on an $8 \%$ or $12 \%$ sodium dodecyl sulfate polyacrylamide gel, and transferred to a polyvinylidene difluoride (PVDF) membrane. The PVDF membranes were washed, blocked with $5 \%$ non-fat milk for $1 \mathrm{~h}$ at room temperature, and then incubated overnight at $4{ }^{\circ} \mathrm{C}$ with primary antibodies, including rabbit polyclonal anti-HES1(1:250, Abcam, Cambridge, MA, USA), mouse monoclonal anti-Fibronectin (1:5000, Abcam, Cambridge, MA, USA), mouse monoclonal anti- $\alpha$-SMA (1:1000, Sigma-Aldrich, St. Louis, MO, USA), rabbit polyclonal anti-Collagen I (1:2000, Abcam, Cambridge, MA, USA), and mouse monoclonal anti-Laminin-5 (1:500, R\&D Systems, Minneapolis, MN, USA). On the next day, the membranes were washed and incubated with corresponding horseradish peroxidase-conjugated secondary antibodies (Tianjin Sungene Biotech Co., Ltd., Tianjin, China) at room temperature for $2 \mathrm{~h}$. Following intensive washes, protein signals were visualized by enhanced chemiluminescence plus reagents (Millipore, Billerica, MA, USA). The images were captured using a Multispectral Imaging System (Biospectrum AC Chemi HR 410, UVP, LLC, Upland, CA, USA). The blots were then stripped and incubated with a mouse monoclonal antibody to GAPDH (1:5000, Cell Signaling Technology, Danvers, MA, USA) to subserve an internal standard. The optical densities of target proteins were quantified by Quantity One (Bio-Rad, Hercules, CA, USA) and normalized to those of GAPDH.

\section{Immunofluorescence}

The HTMCs were seeded on coverslips in a 24well plate with a density of $8 \times 10^{4}$ cells / well. The cells were subjected to oxidative stress for $2 \mathrm{~h}$, and washed with pre-warmed Dulbecco's Phosphate Buffered Saline (DPBS) twice, fixed with 4\% paraformaldehyde (PFA) for $30 \mathrm{~min}$ at $4{ }^{\circ} \mathrm{C}$. The cells were permeabilized with $0.1 \%$ Triton X-100 (Sigma-Aldrich, St. Louis, MO, USA) in DPBS for 30 min and blocked with $5 \%$ goat serum (Life Technologies, Grand Island, NY, USA) for $2 \mathrm{~h}$ at room temperature. The cells were then incubated overnight at $4{ }^{\circ} \mathrm{C}$ with primary antibodies, including anti-Fibronectin (Abcam, Cambridge, MA, USA), anti-Collagen I (Abcam, Cambridge, MA, USA), anti-Laminin-5 (R\&D Systems, Minneapolis, MN, USA), anti- $\alpha$-SMA (Sigma-Aldrich, St. Louis, MO, USA), and anti-HES1 (Abcam, Cambridge, MA, USA)(all diluted at 1:100). The HTMCs were washed and incubated with Alexa 488-conjugated secondary antibodies (Life Technologies, Grand Island, NY, USA) for $2 \mathrm{~h}$ at room temperature. Afterwards, the coverslips were mounted with ProLong Gold Antifade with DAPI (Life Technologies, Grand Island, NY, USA). The pictures were taken by the cellSens Standard electronic system (Olympus Optical Co. Ltd., Tokyo, Japan) under a fluorescence microscope (BX51, Olympus Optical Co. Ltd., Tokyo, Japan) using identical optical parameters.

\section{Migration assay}

The HTMCs, either cultured under normal condition or at $5 \mathrm{~d}$ post viral transduction, were treated with $\mathrm{H}_{2} \mathrm{O}_{2}$ for $2 \mathrm{~h}$. Then the cells were digested and counted with Trypan Blue staining. The live cells were plated in 6-well plates at a density of $1 \times 10^{6}$ cells / well, and incubated in serum free DMEM (4.5 g/L glucose, Life Technologies, Grand Island, NY, USA) at $37^{\circ} \mathrm{C}$ for $24 \mathrm{~h}$. Afterwards, migration assay was performed using Transwell chambers in a 24-well plate format (Corning Costar, Cambridge, MA, USA). The chambers were balanced with DMEM (4.5 g/L glucose, Life Technologies, Grand Island, NY, USA) for $1 \mathrm{~h}$ at $37^{\circ} \mathrm{C}$. Each upper chamber was seeded with $1.5 \times 10^{5}$ HTMCs in $100 \mu \mathrm{LMEM}$ (4.5 g/L glucose, Life Technologies, Grand Island, NY, USA), and the lower chamber was filled with $500 \mu \mathrm{l}$ complete culture media. At $10 \mathrm{~h}$ after seeding, the cells were briefly rinsed with PBS, fixed and stained with $0.1 \%$ crystal violet (dissolved in anhydrous ethanol, Sigma-Aldrich, St. Louis, MO, USA) for $20 \mathrm{~min}$, and washed 3 times with water. The cells at inner bottom of upper chamber were wiped off with a damped cotton swab. The membranes of upper chambers were air dried, circumcised, and mounted on the slides with neutral balsam (Sigma-Aldrich, St. Louis, MO, USA). The pictures were taken using the cellSens Standard electronic system (Olympus Optical Co. Ltd., Tokyo, Japan) under a light microscope (BX51, Olympus Optical Co. Ltd., Tokyo, Japan). The membrane was divided into 4 quadrants, and 3 representative pictures were acquired for each quadrant. The numbers of cells on the 3 pictures were averaged to represent cell migration in each quadrant, and the averages representing 4 quadrants were added up to represent cell migration on each membrane.

\section{Proliferation assays}

The HTMCs, either cultured under normal condition or at $5 \mathrm{~d}$ post viral transduction, were subjected to the oxidative stress followed by Trypan Blue counting as described in Migration assay.

\section{CCK-8 assay}

The cells were seeded at a density of $5 \times 10^{3}$ cells / well in complete culture media in a 96-well plate. At 24 and $48 \mathrm{~h}$ after seeding, the complete culture media were replaced with $100 \mu \mathrm{DMEM}$ (4.5 g/L glucose, Life Technologies, Grand Island, NY, USA) containing 10 $\mu \mathrm{C}$ CK-8 reagent (Dojindo Laboratories, Kumamoto, Japan). The A450 was measured as described above. Cell proliferation was expressed as percentage of the normal control. 


\section{Ki67 staining}

The cells were seeded at a density of $2 \times 10^{4}$ cells / well on coverslips in a 24 -well plate. The cells were cultured in complete culture media for 24 or $48 \mathrm{~h}$. Then the cells were fixed with 4\% PFA, washed with DPBS, and treated with the blocking and permealization buffer $(0.1 \%$ Tween $20,1 \%$ bovine serum albumin (BSA), $10 \%$ rabbit serum, and $0.3 \mathrm{M}$ glycine in DPBS, SigmaAldrich, St. Louis, MO, USA) at room temperature for $1 \mathrm{~h}$. The cells were incubated with the primary antibody rabbit polyclonal anti-Ki67 (diluted at 1:1000, Abcam, Cambridge, MA, USA) at $4{ }^{\circ} \mathrm{C}$ overnight. The cells were incubated with Alexa 488-conjugated secondary antibody at room temperature for $1.5 \mathrm{~h}$. Then the coverslip mounting and picture taking were performed as described in Immunofluorescence. The quantification of Ki67positive staining was conducted as described in Migration assay.

\section{Edu assay}

The cells were seeded on coverslips in a 24-well plate in complete culture media at a density of $2 \times 10^{4}$ cells / well. Then Edu assay was performed using a ClickiT Edu imaging Kit (Thermo Scientific, Waltham, MA, USA). When the cells were cultured at 24 or $48 \mathrm{~h}, 10 \mu \mathrm{M}$ Edu was added to label the synthesizing DNA. Twenty hours after addition, the integrated Edu was detected according to the manufacturer's protocol. The coverslip mounting, picture taking, and quantification of Edupositive staining was performed as described above.

\section{Statistical analyses}

The data were analyzed by Graphpad (GraphPad Software, Inc., La Jolla, CA, USA) software. The data were examined by D'Agostino and Pearson omnibus normality test, those with Gaussian distribution were examined by Levene test to confirm homogeneity of variance, and then analyzed by unpaired $t$ test or Oneway or Two-way ANOVA followed by Tukey post hoc; the data with nonparametric distribution were analyzed by Kruskal-Wallis test followed by Dunn's post hoc. A $p$ value less than 0.05 was considered significant.

\section{ACKNOWLEDGMENTS}

We thank Dr. Xi Wang, Dr. Xudong Wu, and members of laboratories of J.W. and H.Y. for technical assistance, insightful discussions, and critical comments. This research work was supported by the grants from the National Natural Science Foundation of China (\# 81270994 and \# 81070725 to J.W.), the 973 Chinese National Basic Research Program (\# 2012CBA01305 and \# 2012CB932503 to H.Y.), and the Tianjin Municipal Science and Technology Commission (\# 14JCZDJC36200 to C.Q.).

\section{CONFLICTS OF INTEREST}

The authors declare no competing interests.

\section{Author contributions}

J.W. and H.Y. conceived and designed experiments and obtained funding. L.X., R.G., Y.Z., W.S., Y.Q., and Q.W. performed the experiments; Q.W., Z.G., and C.Q. analyzed the data; L.X. wrote the first draft of the manuscript, Y.Z. extensively revised, formatted, and submitted versions of the manuscript. J.W. and H.Y. previewed the manuscript. All authors participated in data discussions and approved the submitted versions.

\section{REFERENCES}

1. Quigley HA, Broman AT. The number of people with glaucoma worldwide in 2010 and 2020. Br J Ophthalmol. 2006; 90:262-267.

2. Janssen SF, Gorgels TG, Ramdas WD, Klaver CC, van Duijn CM, Jansonius NM, Bergen AA. The vast complexity of primary open angle glaucoma: disease genes, risks, molecular mechanisms and pathobiology. Prog Retin Eye Res. 2013; 37:31-67.

3. Caprioli J, Coleman AL. Intraocular pressure fluctuation a risk factor for visual field progression at low intraocular pressures in the advanced glaucoma intervention study. Ophthalmology. 2008; 115:1123-1129.

4. Nemesure B, Honkanen R, Hennis A, Wu SY, Leske MC. Incident open-angle glaucoma and intraocular pressure. Ophthalmology. 2007; 114:1810-1815.

5. Heijl A, Leske MC, Bengtsson B, Hyman L, Bengtsson B, Hussein M. Reduction of intraocular pressure and glaucoma progression: results from the Early Manifest Glaucoma Trial. Arch Ophthalmol. 2002; 120:1268-1279.

6. Li T, Lindsley K, Rouse B, Hong H, Shi Q, Friedman DS, Wormald R, Dickersin K. Comparative Effectiveness of First-Line Medications for Primary Open-Angle Glaucoma: A Systematic Review and Network Meta-analysis. Ophthalmology. 2016; 123:129-140.

7. Gual A, Llobet A, Gilabert R, Borras M, Pales J, Bergamini $\mathrm{MV}$, Belmonte C. Effects of time of storage, albumin, and osmolality changes on outflow facility (C) of bovine anterior segment in vitro. Invest Ophthalmol Vis Sci. 1997; 38:2165-2171

8. Wiederholt M, Bielka S, Schweig F, Lutjen-Drecoll E, Lepple-Wienhues A. Regulation of outflow rate and resistance in the perfused anterior segment of the bovine eye. Exp Eye Res. 1995; 61:223-234.

9. Vranka JA, Kelley MJ, Acott TS, Keller KE. Extracellular matrix in the trabecular meshwork: intraocular pressure regulation and dysregulation in glaucoma. Exp Eye Res. $2015 ; 133: 112-125$. 
10. Zou H, Yuan R, Zheng Q, Huo Y, Lang M, Ji S, Zheng $\mathrm{Z}$, Ye J. Fluctuations in intraocular pressure increase the trabecular meshwork extracellular matrix. Cell Physiol Biochem. 2014; 33:1215-1224.

11. Majsterek I, Malinowska K, Stanczyk M, Kowalski M, Blaszczyk J, Kurowska AK, Kaminska A, Szaflik J, Szaflik JP. Evaluation of oxidative stress markers in pathogenesis of primary open-angle glaucoma. Exp Mol Pathol. 2011; 90:231-237.

12. Babizhayev MA. Biomarkers and special features of oxidative stress in the anterior segment of the eye linked to lens cataract and the trabecular meshwork injury in primary open-angle glaucoma: challenges of dual combination therapy with $\mathrm{N}$-acetylcarnosine lubricant eye drops and oral formulation of nonhydrolyzed carnosine. Fundam Clin Pharmacol. 2012; 26:86-117.

13. Sacca SC, Izzotti A. Oxidative stress and glaucoma: injury in the anterior segment of the eye. Prog Brain Res. 2008; 173:385-407.

14. Kageyama R, Ohtsuka T, Kobayashi T. The Hes gene family: repressors and oscillators that orchestrate embryogenesis. Development. 2007; 134:1243-1251.

15. Kageyama R, Ohtsuka T, Kobayashi T. Roles of Hes genes in neural development. Dev Growth Differ. 2008; 50:S97-S103.

16. Ueo T, Imayoshi I, Kobayashi T, Ohtsuka T, Seno H, Nakase H, Chiba T, Kageyama R. The role of Hes genes in intestinal development, homeostasis and tumor formation. Development. 2012; 139:1071-1082.

17. Hu M, Ou-Yang HF, Wu CG, Qu SY, Xu XT, Wang P. Notch signaling regulates collalpha1 and collalpha2 expression in airway fibroblasts. Exp Biol Med (Maywood). 2014; 239:1589-1596.

18. Plantier L, Crestani B, Wert SE, Dehoux M, Zweytick B, Guenther A, Whitsett JA. Ectopic respiratory epithelial cell differentiation in bronchiolised distal airspaces in idiopathic pulmonary fibrosis. Thorax. 2011; 66:651-657.

19. Xiao Z, Zhang J, Peng X, Dong Y, Jia L, Li H, Du J. The Notch gamma-secretase inhibitor ameliorates kidney fibrosis via inhibition of TGF-beta/Smad2/3 signaling pathway activation. Int $\mathrm{J}$ Biochem Cell Biol. 2014; 55:65-71.

20. Cavet ME, Vollmer TR, Harrington KL, VanDerMeid K, Richardson ME. Regulation of Endothelin-1-Induced Trabecular Meshwork Cell Contractility by Latanoprostene Bunod. Invest Ophthalmol Vis Sci. 2015; 56:4108-4116.

21. Hudson BD, Kelly ME. Identification of novel competing beta2AR phospho-extracellular signal regulated kinase $1 / 2$ signaling pathways in human trabecular meshwork cells. J Ocul Pharmacol Ther. 2012; 28:17-25.

22. Li T, Zhang H, Liang F. Existence of heme oxygenasecarbon monoxide-cyclic guanosine monophosphate pathway in human trabecular meshwork cells in vitro. $\mathrm{J}$ Huazhong Univ Sci Technolog Med Sci. 2004; 24:173-177.
23. Shen W, Han Y, Huang B, Qi Y, Xu L, Guo R, Wang X, Wang J. MicroRNA-483-3p Inhibits Extracellular Matrix Production by Targeting Smad4 in Human Trabecular Meshwork Cells. Invest Ophthalmol Vis Sci. 2015; 56:8419-8427.

24. Wallace DM, Clark AF, Lipson KE, Andrews D, Crean JK, O'Brien CJ. Anti-connective tissue growth factor antibody treatment reduces extracellular matrix production in trabecular meshwork and lamina cribrosa cells. Invest Ophthalmol Vis Sci. 2013; 54:7836-7848.

25. Scholzen T, Gerdes J. The Ki-67 protein: from the known and the unknown. J Cell Physiol. 2000; 182:311-322.

26. Salic A, Mitchison TJ. A chemical method for fast and sensitive detection of DNA synthesis in vivo. Proc Natl Acad Sci U S A. 2008; 105:2415-2420.

27. Spector A, Garner WH. Hydrogen peroxide and human cataract. Exp Eye Res. 1981; 33:673-681.

28. Zanon-Moreno V, Marco-Ventura P, Lleo-Perez A, PonsVazquez S, Garcia-Medina JJ, Vinuesa-Silva I, MorenoNadal MA, Pinazo-Duran MD. Oxidative stress in primary open-angle glaucoma. J Glaucoma. 2008; 17:263-268.

29. Chen M, Liu B, Gao Q, Zhuo Y, Ge J. Mitochondria-targeted peptide MTP-131 alleviates mitochondrial dysfunction and oxidative damage in human trabecular meshwork cells. Invest Ophthalmol Vis Sci. 2011; 52:7027-7037.

30. Yu AL, Fuchshofer R, Kampik A, Welge-Lussen U. Effects of oxidative stress in trabecular meshwork cells are reduced by prostaglandin analogues. Invest Ophthalmol Vis Sci. 2008; 49:4872-4880.

31. Luna C, Li G, Qiu J, Epstein DL, Gonzalez P. Role of miR$29 \mathrm{~b}$ on the regulation of the extracellular matrix in human trabecular meshwork cells under chronic oxidative stress. Mol Vis. 2009; 15:2488-2497.

32. Acott TS, Kelley MJ. Extracellular matrix in the trabecular meshwork. Exp Eye Res. 2008; 86:543-561.

33. Vranka JA, Bradley JM, Yang YF, Keller KE, Acott TS. Mapping molecular differences and extracellular matrix gene expression in segmental outflow pathways of the human ocular trabecular meshwork. PLoS One. 2015; 10:e122483.

34. Yang Y, Duan W, Liang Z, Yi W, Yan J, Wang N, Li Y, Chen W, Yu S, Jin Z, Yi D. Curcumin attenuates endothelial cell oxidative stress injury through Notch signaling inhibition. Cell Signal. 2013; 25:615-629.

35. Kamarehei M, Yazdanparast R. Modulation of notch signaling pathway to prevent $\mathrm{H} 2 \mathrm{O} 2$ /menadione-induced SK-N-MC cells death by EUK134. Cell Mol Neurobiol. 2014; 34:1037-1045.

36. Yu L, Liang H, Lu Z, Zhao G, Zhai M, Yang Y, Yang J, Yi D, Chen W, Wang X, Duan W, Jin Z, Yu S. Membrane receptor-dependent Notch1/Hes1 activation by melatonin protects against myocardial ischemia-reperfusion injury: in vivo and in vitro studies. J Pineal Res. 2015; 59:420-433. 
37. Ferreira SM, Lerner SF, Brunzini R, Evelson PA, Llesuy SF. Oxidative stress markers in aqueous humor of glaucoma patients. Am J Ophthalmol. 2004; 137:62-69.

38. Honjo M, Tanihara H, Inatani M, Kido N, Sawamura T, Yue BY, Narumiya S, Honda Y. Effects of rho-associated protein kinase inhibitor Y-27632 on intraocular pressure and outflow facility. Invest Ophthalmol Vis Sci. 2001; 42:137-144.

39. Koga T, Koga T, Awai M, Tsutsui J, Yue BY, Tanihara H. Rho-associated protein kinase inhibitor, Y-27632, induces alterations in adhesion, contraction and motility in cultured human trabecular meshwork cells. Exp Eye Res. 2006; 82:362-370.

40. Clark AF, Wilson K, McCartney MD, Miggans ST, Kunkle M, Howe W. Glucocorticoid-induced formation of cross-linked actin networks in cultured human trabecular meshwork cells. Invest Ophthalmol Vis Sci. 1994; 35:281-294.

41. Aoyagi-Ikeda K, Maeno T, Matsui H, Ueno M, Hara K, Aoki Y, Aoki F, Shimizu T, Doi H, Kawai-Kowase K,
Iso T, Suga T, Arai M, Kurabayashi M. Notch induces myofibroblast differentiation of alveolar epithelial cells via transforming growth factor-\{beta\}-Smad3 pathway. Am J Respir Cell Mol Biol. 2011; 45:136-144.

42. Sassoli C, Chellini F, Pini A, Tani A, Nistri S, Nosi D, Zecchi-Orlandini S, Bani D, Formigli L. Relaxin prevents cardiac fibroblast-myofibroblast transition via notch-1mediated inhibition of TGF-beta/Smad3 signaling. PLoS One. 2013; 8:e63896.

43. Zhang Y, Bo Q, Wu W, Xu C, Yu G, Ma S, Yang Q, Cao Y, Han Q, Ru Y, Liu X, Hua WR, Wang FE, Zhang X, Li X. alpha-Melanocyte-stimulating hormone prevents glutamate excitotoxicity in developing chicken retina via MC4Rmediated down-regulation of microRNA-194. Sci Rep. 2015; 5:15812.

44. Ru Y, Huang Y, Liu H, Du J, Meng Z, Dou Z, Liu X, Wei RH, Zhang Y, Zhao S. alpha-Melanocyte-stimulating hormone ameliorates ocular surface dysfunctions and lesions in a scopolamine-induced dry eye model via PKACREB and MEK-Erk pathways. Sci Rep. 2015; 5:18619. 